Revista Brasil. Bot., V.32, n.1, p.89-94, jan.-mar. 2009

\title{
Duas novas espécies de Paspalum L. (Poaceae: Paniceae) do Brasil ${ }^{1}$
}

\author{
REGINA CÉLIA DE OLIVEIRA ${ }^{2,3,4}$ e JOSÉ FRANCISCO MONTENEGRO VALLS ${ }^{3}$
}

(recebido: 30 de agosto de 2007; aceito: 04 de dezembro de 2008)

\begin{abstract}
Two new species of Paspalum L. (Poaceae: Paniceae) from Brazil). Two new species of Paspalum L. belonging to the informal group Plicatula are described and illustrated. Paspalum laurentii L., from Rio Grande do Sul, southern Brazil, is mainly recognized by the long trichomes on the margins of the rachis and pedicel. Paspalum longipedicellatum L., from Mato Grosso do Sul, west-central Brazil, is flabellate at the base, with short rhizomes covered by velvety cataphylls, the trichomes yellowish, and it has long spikelet pedicels, specially in the proximal portion of each raceme.
\end{abstract}

Key words - Brazil, Gramineae, grasses, Mato Grosso do Sul state, Plicatula group, Rio Grande do Sul state

RESUMO - (Duas novas espécies de Paspalum L. (Poaceae: Paniceae) do Brasil). Duas espécies novas de Paspalum L., grupo informal Plicatula, são descritas e ilustradas. Paspalum laurentii L., do Rio Grande do Sul, é reconhecida, principalmente, pelos tricomas longos na margem da ráquis e do pedicelo. Paspalum longipedicellatum L., do Mato Grosso do Sul, possui base flabelada, rizomas curtos com catáfilos velutinos, cobertos por tricomas amarelados, e pedicelos das espiguetas longos, especialmente na porção proximal do racemo.

Palavras-chave - Brasil, Gramineae, gramíneas, grupo Plicatula, Mato Grosso do Sul, Rio Grande do Sul

\section{Introdução}

Paspalum L. compreende cerca de 400 espécies (Chase 1929) que distribuem-se principalmente pelo continente americano, ocorrendo de forma esporádica nas demais regiões tropicais e subtropicais do planeta (Chase 1929, Clayton \& Renvoize 1986). Estima-se em 220 o número de espécies de Paspalum no Brasil (Valls 1994), e a região central do país é o centro de diversidade do gênero (Chase 1929). Paspalum engloba o maior número de espécies com potencial forrageiro, dentre os gêneros de gramíneas brasileiras (Valls 1994). Muitas espécies de Paspalum são ecologicamente dominantes em diversas formações campestres, como pântanos, savanas e pradarias; também são encontradas espécies ruderais e de bosques, em dunas costeiras e habitats halófitos ou alagados (Zuloaga \& Morrone 2005).

Estudos taxonômicos abrangentes com Paspalum foram realizados por Chase (1929 e em um manuscrito inédito sobre as espécies sul americanas), Pilger (1940) e Zuloaga \& Morrone (2005). Chase (1929) subdividiu

1. Parte da tese de doutorado do primeiro autor, Programa de Pósgraduação em Biologia Vegetal da Universidade Estadual de Campinas, Campinas.

2. Universidade Federal Rural do Semi-Árido (Ufersa), Setor de Fitossanidade, Campus Universitário, Caixa Postal 137, 59700-970 Mossoró, RN.

3. Embrapa Recursos Genéticos e Biotecnologia (Cenargen), PqEB Parque Estação Biológica, W5 Final Norte, Caixa Postal 02372, 70770-900 Brasília, DF.

4._Autor para correspondência: reginacelia@ufersa.edu.br
Paspalum em dois subgêneros - Paspalum e Ceresia (Pers.) Rchb. No primeiro, reconheceu uma série de grupos informais. Embora não possuam categoria taxonômica definida e sejam considerados artificiais, tais grupos são amplamente utilizados e alguns autores têm discutido a possível monofilia de alguns deles (Rua \& Aliscioni 2002, Denham et al. 2002, Souza-Chies et al. 2006).

O grupo informal Plicatula engloba espécies morfologicamente afins a Paspalum plicatulum Michx., com espiguetas com convexidade geralmente pronunciada, antécio superior castanho escuro e brilhante e ondulações transversais no lema inferior. Com exceção de $P$. scrobiculatum L. e espécies relacionadas, Plicatula têm ocorrência restrita ao continente americano, dos Estados Unidos até o Uruguai e Argentina. No Brasil, o grupo está representado por cerca de trinta espécies anuais e perenes, algumas endêmicas de determinadas regiões e outras de ampla distribuição pelo continente americano (Oliveira 2004).

Durante a revisão taxonômica das espécies brasileiras de Paspalum, grupo Plicatula, detectou-se a ocorrência de duas espécies ainda não descritas.

\section{Material e métodos}

O presente estudo fundamentou-se em explorações de campo, na análise de plantas cultivadas na antiga Coleção Viva de Gramíneas Nativas da Estação Experimental Agronômica da Universidade Federal do Rio Grande do Sul, situada em Guaíba, RS (hoje Eldorado do Sul) e em telado na Embrapa Recursos Genéticos e Biotecnologia (Brasília, 
DF) bem como na triagem de exsicatas ou de imagens digitalizadas de 29 herbários brasileiros, argentinos e uruguaios, dos quais apenas três, BAA, BLA e CEN, cujos acrônimos são encontrados em Holmgren \& Holmgren (1998), dispõem de exsicatas dos materiais em pauta.

\section{Resultados e discussão}

Paspalum laurentii R. C. Oliveira \& Valls, sp. nov. Tipo: BRASIL. Rio GRANDE do Sul: "Guaíba, canteiro 838”, 27-XII-1973, I. L. Barreto s.n. (holótipo BLA 9156; isótipo CEN).

Figura 1

Planta perennis, caespitosa, sine rhizomatibus; culmi 30-60 cm longi, laminae foliorum 0,1-0,3 cm latae, lineares; spiculae dense pilosae; pedicelli et rhachis ciliis hyalinis (2)3-5 $\mathrm{mm}$ longis praediti.

Plantas perenes, cespitosas. Rizomas ausentes. Colmos floríferos 30-60 cm alt., eretos, não ramificados, paucinodes; nós barbados, inconspícuos. Bainhas 4-6 cm compr., mais longas que os entrenós, as jovens velutíneas na porção distal, as mais velhas com poucos tricomas; aurículas ausentes. Lígula 1,5-2,5 mm compr., membranosa, erosa; colar ausente. Lâminas 10-18 × 0,1-0,3 cm, lineares, as jovens conduplicadas e densamente velutinas em ambas as superfícies, as mais velhas planas e pubescentes, margens glabras. Pedúnculos glabros. Inflorescência terminal com 2-5 ramos unilaterais espiciformes, os proximais com 4-5,3 cm compr., os distais com 3,5-4,6 cm compr., terminando numa espigueta; pulvino com tricomas longos; ráquis $c a$. 0,8 mm larg., com tricomas longos de (2-)3-7 mm compr., especialmente nas margens próximas ao ponto de inserção dos pedicelos e na porção mediana do ramo da inflorescência. Espiguetas pareadas, 2,2 × 1,7 mm, ovadas, obtusas na base, a espigueta proximal de cada par, em geral, abortada na porção distal do ramo da inflorescência; gluma inferior ausente; gluma superior tão longa quanto o antécio superior, densamente pilosa, 5-nervada, somente a nervura central conspícua; lema inferior tão longo quanto o antécio superior, densamente piloso, 3-nervado, apenas a nervura central conspícua; antécio superior $2,2 \times 1,7 \mathrm{~mm}$, obovado, plano-convexo, glabro; lodículas 2, ca. 0,1 mm compr.; estames 3 , anteras $1 \mathrm{~mm}$ compr., amarelas, com as paredes laterais vináceas; estigmas 2, vináceos. Cariopse não vista.

Parátipos: BRASIL. Rio GRANDE Do Sul: Alegrete, "Faz. Inhanduy, em campo", 13-XII-1955, I.L. Barreto, s.n. (BLA 1328). Idem, ibidem (BLA 1329); "Guaíba, canteiro NF 838”, 18-XII-1964, s.col., s.n. (BLA 4650);
São Gabriel, Vacacaí, Granja São José, I-1974, I. L. Barreto s.n. (BLA 9157).

Paspalum laurentii foi citada como espécie nova por Barreto (1974), sob o epíteto inédito P. parodii nom. nud. O nome proposto por Barreto não é aqui mantido, diante da existência de $P$. parodianum Henrard, o que poderia levar a confusões futuras. Mantém-se, no entanto, a homenagem ao eminente agrostólogo argentino, Professor Lorenzo ("Laurentius") R. Parodi, como era desejo do Dr. Ismar Leal Barreto (comunicação pessoal), em reconhecimento a sua ampla contribuição para a compreensão das gramíneas sul-americanas.

Barreto havia mencionado a existência de vários isótipos, os quais não foram localizados até o presente. Como não há coletas recentes desta espécie e, passados tantos anos, não havia mais plantas disponíveis em canteiros experimentais, foi realizada uma expedição à localidade de ocorrência do material originalmente cultivado em Guaíba (São Gabriel, RS, Granja São José, Potreiro do Bocó, 30²7’58” S, 054¹6’42” W). A visita foi realizada em janeiro de 2000 , portanto, em período coincidente com coletas anteriores em floração, e guiada pelo coletor original, Dr. Ismar Leal Barreto, mas nenhuma população foi reencontrada. Embora também existam exsicatas documentais de uma coleta realizada por Barreto em Alegrete, em 1955, a cerca de $180 \mathrm{~km}$ do local em São Gabriel, é possível que esta espécie esteja seriamente ameaçada, pelas drásticas mudanças impostas à vegetação do Rio Grande do Sul pelo avanço da agricultura mecanizada, desde a década de 1960.

Paspalum laurentii distingue-se das espécies brasileiras do grupo Plicatula pelo pequeno porte, quando comparado com as demais espécies cespitosas perenes, pelas lâminas estreitas e densamente velutíneas e, principalmente, pelos longos tricomas ((2)3-7 mm de comprimento) sobre a ráquis e margens dos pedicelos.

Conforme Barreto (1974), a espécie floresce de novembro a janeiro, sazonando em março e abril. Paspalum laurentii é restrita à região da Campanha do Estado do Rio Grande do Sul, crescendo em solos graníticos secos, sendo intensivamente consumida pelo gado (Barreto 1974). A partir de plantas originalmente coletadas no Município de São Gabriel, a espécie fora incluída no canteiro NF 838 da antiga Coleção Viva de Gramíneas Nativas da Estação Experimental Agronômica da Universidade Federal do Rio Grande do Sul, no atual Município de Eldorado do Sul, em área, à época, pertencente ao Município de Guaíba. Dessa coleção viva, foram coletadas as exsicatas para incorporação ao Herbário do Laboratório de Agrostologia da Secretaria da Agricultura (BLA 4650 e o holótipo BLA 9156), em 


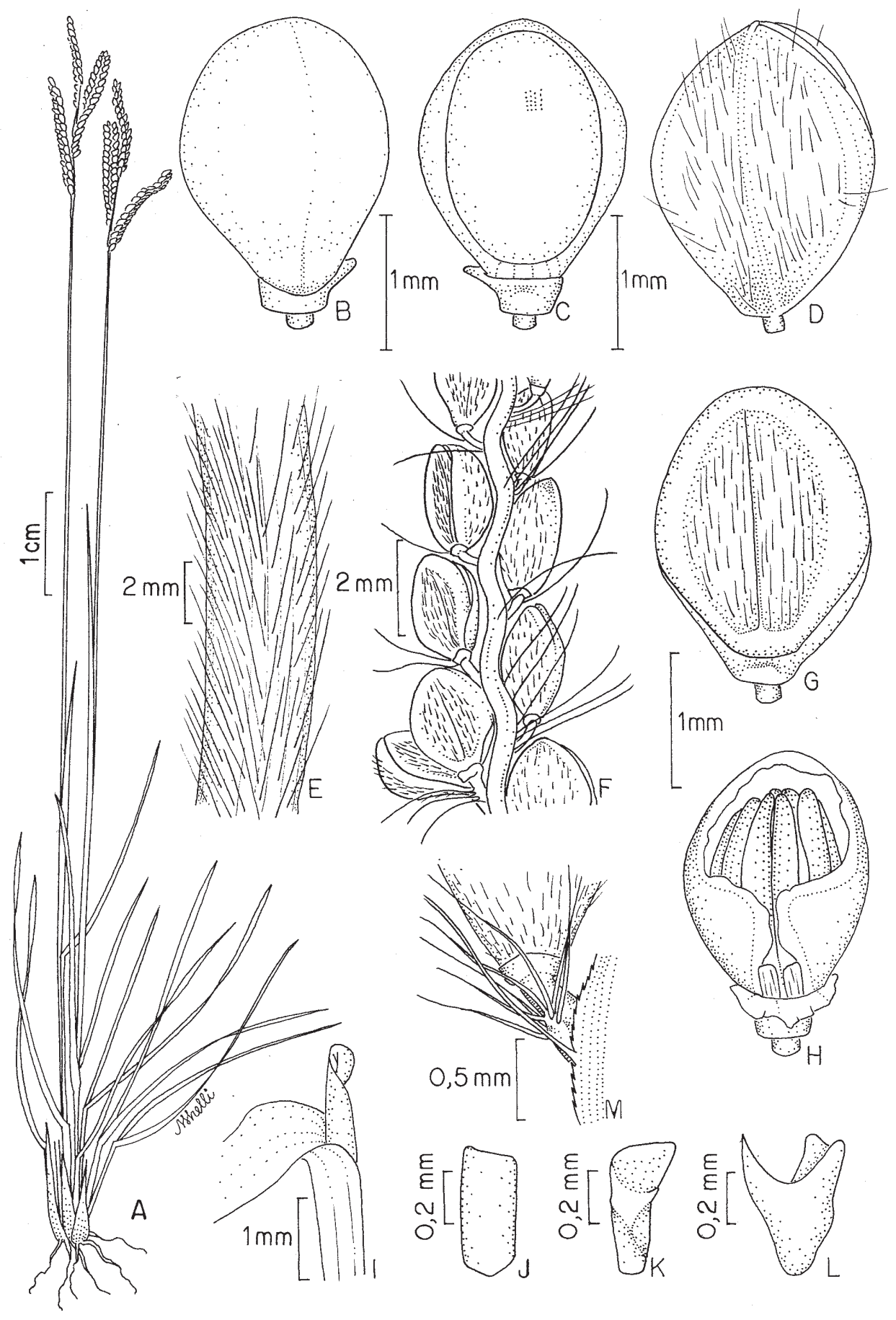

Figura 1. Paspalum laurentii R. C. Oliveira \& Valls. A. Hábito. B. Antécio superior, visão do lema. C. Antécio superior, visão da pálea. D. Espigueta, visão da gluma superior. E. Porção da bainha jovem detalhando pilosidade. F. Porção do ramo da inflorescência com espiguetas e tricomas. G. Espigueta, visão do lema inferior. H. Pálea superior e estames. I. Lígula. J, K e L. Lodículas nas posições abaxial, adaxial e lateral. M. Porção proximal da espigueta, pedicelos e margem da ráquis evidenciando os tricomas (s.col., s.n., BLA 4650).

Figure 1. Paspalum laurentii R. C. Oliveira \& Valls. A. Habit. B. Upper anthecium, lemma view. C. Upper anthecium, palea view. D. Spikelet, upper glume view. E. Portion of young sheath showing hairiness. F. Portion of a raceme with spikelets and trichomes. G. Spikelet, lower lemma view. H. Upper palea and stamens. I. Ligule. J, K and L. Lodicules, abaxial, adaxial and lateral (position) views, respectively. M. Proximal portion of spikelets, pedicels and margins of the rachis with trichomes (s.col., s.n., BLA 4650). 


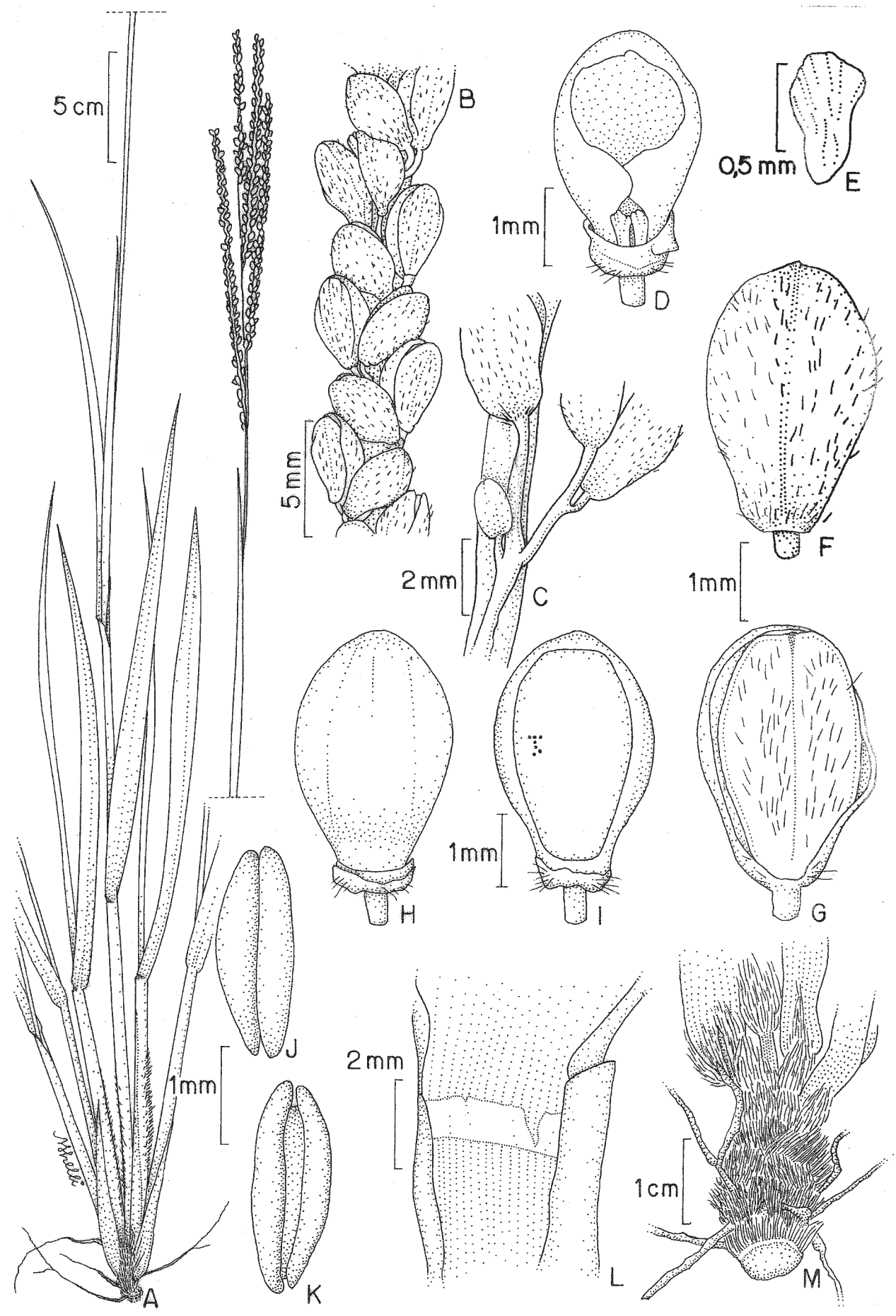

Figura 2. Paspalum longipedicellatum R. C. Oliveira \& Valls. A. Hábito. B. Porção do ramo da inflorescência com espiguetas. C. Detalhe da porção proximal da inflorescência com espigueta abortada de ordem de ramificação maior que dois e pedicelos. D. Pálea superior. E. Lodícula. F. Espigueta, visão da gluma superior. G. Espigueta, visão do lema inferior. H. Antécio superior, visão do lema superior. I. Antécio superior, visão da pálea superior. J e K. Anteras. L. Lígula. M. Rizoma com catáfilos vilosos (Valls et al. 9262, CEN).

Figure 2. Paspalum longipedicellatum R. C. Oliveira \& Valls. A. Habit. B. Portion of a raceme with spikelets. C. Proximal portion of the racemes with abortive spikelets at branching order above two and pedicels. D. Upper palea. E. Lodicule. F. Spikelet, upper glume view. G. Spikelet, lower lemma view. H. Upper anthecium, upper lemma view. I. Upper anthecium, upper palea view. J and K. Anthers. L. Ligule. M. Rhizomes covered by villous cataphylls (Valls et al. 9262, CEN). 
Porto Alegre, RS. Também dessa coleção viva foram obtidas as inflorescências para a análise citogenética, que revelou a condição diplóide de $P$. laurentii, com $2 n=20$ cromossomos (Barreto 1974), uma característica pouco freqüente em espécies de Paspalum do grupo Plicatula.

Paspalum longipedicellatum R. C. Oliveira \& Valls, sp. nov. Tipo: BRASIL. MAto Grosso do Sul: Rio Verde de Mato Grosso, "entrada da estrada que desce para a Serra da Alegria a partir da BR-163, entre Rio Verde e Coxim, 1845'10" S, 05449'20”' W, 20-X-1985, J. F. M. Valls, A. Pott \& L.B. Bianchetti 9262 (holótipo CEN; isótipo BAA).

\section{Figura 2}

Planta perennis, caespitosa, basin versus flabellata, rhizomatibus brevibus et verticalibus, cataphyllis velutinis obtectis, trichomata flavida; vaginae velutinae praecipue basin versus, laminae basales, $30-38 \times 1-1,2 \mathrm{~cm}$, planae; pedicelli racemis basis 1,2-4 mm longi; spiculae 3,5 $\times 2,5 \mathrm{~mm}$, basin versus fortiter attenuatae.

Plantas perenes, cespitosas, base flabelada. Rizomas curtos cobertos por catáfilos velutinas, os tricomas conspicuamente amarelados. Colmos floríferos $52-89 \mathrm{~cm}$ alt., eretos, não ramificados; nós densamente pilosos, inconspícuos. Bainhas 14-20 cm compr., mais longas que os entrenós, velutinas, em especial na porção proximal; aurículas presentes, curtas. Lígula 0,9 mm compr., membranosa, truncada; colar castanho. Lâminas 30-38 × 1-1,2 cm, planas, linear-lanceoladas, antocianosadas, especialmente na superfície abaxial, levemente pilosas na superfície adaxial, densamente pilosas na abaxial, os tricomas tuberculados, margens escabras. Inflorescência terminal, com 4-5 ramos unilaterais espiciformes, eretos, os proximais de 15-16,5 cm compr., os distais 5-7,5 cm compr., terminando ou não em uma espigueta; pulvino glabro ou com tricomas curtos; ráquis $0,8 \mathrm{~mm}$ larg., geralmente esparsamente pilosa na porção proximal e glabra ou com alguns tricomas na superfície abaxial distal; pedicelos das espiguetas proximais de primeira ordem 1,2-4 mm compr., nas medianas e distais 1,2-1,5 mm compr., alguns secundários $0,8 \mathrm{~mm}$ comprimento, levemente pilosos. Espiguetas pareadas, 3,5 × 2,5 mm, elíptico-obovadas, atenuadas na porção proximal; gluma inferior ausente; gluma superior do mesmo comprimento do antécio superior, pilosa, 5-7-nervada, as nervuras obscuras; lema inferior tão longo quanto o antécio superior, piloso, 5-nervado, nervuras obscuras, exceto a central; antécio superior 3,5 ×2,5 mm, elíptico-oboval, plano-convexo, com micropelos concentrados na porção distal do lema; lodículas 2, ca. 0,2 mm compr.; estames 3 , anteras ca. 2,3 mm compr., margens alaranjadas e porção central vinácea; estigmas 2 , vináceos. Cariopse não vista.

Essa espécie é conhecida apenas da localidade típica, no topo da escarpa do planalto central que desce ao Pantanal mato-grossense, denominada Serra da Alegria. Foi encontrada em sítios perturbados nas margens do cerrado, com solo arenoso cinzento.

Paspalum longipedicellatum é relacionada a $P$. rojasii Hack. pelo hábito cespitoso, folhas antocianosadas, especialmente na superfície abaxial e pelas espiguetas longas $(3,5 \times 2,5 \mathrm{~mm})$. Paspalum rojasii difere por não possuir base flabelada, pelo estreitamento proximal das lâminas foliares, ausência de pubescência velutina e de tricomas amarelados na base da planta e pelo menor comprimento dos pedicelos das espiguetas proximais de primeira ordem.

Os espécimens de $P$. longipedicellatum apresentaram espiguetas abortadas em ordem de ramificação superior a dois, na porção proximal do ramo unilateral (figura 2C).

$\mathrm{O}$ epíteto específico é uma referência aos longos pedicelos das espiguetas na porção basal dos ramos da inflorescência.

Agradecimentos - Agradecemos à Capes pela bolsa de doutorado concedida e ao CNPq pelo suporte financeiro a muitas das atividades relacionadas à tese e pela bolsa de Produtividade em Pesquisa do segundo autor. Agradecemos também ao Dr. Tarciso Filgueiras pela tradução das diagnoses em latim, revisão do texto e sugestões.

\section{Referências bibliográficas}

BARRETO, I.L. 1974. O gênero Paspalum (Gramineae) no Rio Grande do Sul. Tese de livre docência, Universidade Federal do Rio Grande do Sul, Porto Alegre.

CHASE, A. 1929. The North American species of Paspalum. Contributions from the United States National Herbarium 28:1-310.

CLAYTON, W.D. \& RENVOIZE, S.A. 1986. Genera graminum: grasses of the world. Royal Botanic Gardens, Kew.

DENHAM, S.S., ZULOAGA, F.O. \& MORRONE, O. 2002. Systematic revision and phylogeny of Paspalum subgenus Ceresia (Poaceae: Panicoideae: Paniceae). Annals of the Missouri Botanical Garden 89:337-399.

HOLMGREN, P. K. \& HOLMGREN, H. 1998 [continuously updated]. Index Herbariorum: A global directory of public herbaria and associated staff. New York Botanical Garden's Virtual Herbarium. http://sweetgum.nybg.org/ $\mathrm{ih} /$ (acesso em 3.2006). 
OLIVEIRA, R.C. 2004. O gênero Paspalum L., grupo Plicatula (Poaceae: Paniceae), no Brasil. Tese de doutorado Universidade Estadual de Campinas, Campinas.

PILGER, R.K.F. 1940. Gramineae III. Unterfamilie Panicoideae. In Die Natürlichen Pflanzenfamilen, (A. Engler \& K. Prantl eds.), Verlag Wilhelm Engelmann, Leipzig., 2 ed, $14 \mathrm{e}$, p.1-208.

RUA, G.H. \& ALISCIONI, S.S. 2002. A morphology-based cladistic analysis of Paspalum sect. Pectinata (Poaceae). Systematic Botany 27:489-501.
SOUZA-CHIES, T.T., ESSI, L., RUA, G.H., VALLS, J.F.M. \& MIZ, R.M. 2006. A preliminary approach to the phylogeny of the genus Paspalum (Poaceae). Genetica 126:15-32.

VALLS, J.F.M. 1994. O potencial de plantas forrageiras tropicais americanas. In Anais do Simpósio Brasileiro de Forrageiras e Pastagens, CBNA, Campinas, p.11-24.

ZULOAGA, F.O. \& MORRONE, O. 2005. Revisión de las especies de Paspalum para América del Sur austral (Argentina, Bolívia, Sur del Brasil, Chile, Paraguay y Uruguay). Missouri Botanical Garden Press, St. Louis. 